\title{
Solid Pseudopapillary Tumor of the Pancreas: One Case with a Metastatic Evolution in a Caucasian Woman
}

\author{
Valentin Lestelle ${ }^{a} \quad$ Claire de Coster $^{a} \quad$ Anthony Sarran $^{b} \quad$ Flora Poizat $^{c}$ \\ Jean-Robert Delpero ${ }^{d}$ Jean-Luc Raoul ${ }^{a}$ \\ Departments of ${ }^{a}$ Medical Oncology, ${ }^{b}$ Medical Imaging, ${ }^{c}$ Pathology and ${ }^{d}$ Surgery, \\ Paoli-Calmettes Institute, Marseille, France
}

\section{Key Words}

Solid pseudopapillary tumor $\cdot$ Pancreas · Metastatic evolution · Caucasian woman

\begin{abstract}
We report the case of a Caucasian woman, operated on for a solid pseudopapillary tumor of the pancreas in 2009, who recurred 4 years later with multiple liver metastases requiring liver resection. This disease is infrequent, particularly among the Caucasian population, and metastatic evolution is very rare.

(C) 2015 The Author(s)

Published by S. Karger AG, Basel
\end{abstract}

\section{Introduction}

Solid pseudopapillary tumor (SPPT) of the pancreas, or Frantz's tumor, is very uncommon ( $<1 \%$ of pancreatic tumors) and is associated with a low potential for malignancy. Furthermore, it is often found in young women of Asian origin. After complete surgical resection, its outcome is excellent. We would like to report the case of a European woman who was surgically cured of SPPT of the pancreatic head and then developed liver metastases, requiring surgical resection, within 5 years.

\section{Case Report}

The patient, a woman born in 1946, was treated in 2003 for breast cancer by surgery, radiation therapy and hormonotherapy. In 2009, she developed abdominal pain, and ul-

KARGER 125:s $\quad \begin{aligned} & \text { Prof. Jean-Luc Raoul } \\ & \text { Department of Medical Oncology, Paoli-Calmettes Institute } \\ & 263 \text { boulevard de Sainte Marguerite } \\ & \text { FR-13273 Marseille (France) } \\ & \text { E-Mail raouljl @ipc.unicancer.fr }\end{aligned}$


Lestelle et al.: Solid Pseudopapillary Tumor of the Pancreas: One Case with a Metastatic Evolution in a Caucasian Woman

trasound examination revealed a large tumor of the pancreatic head. On CT scan, this $60 \times$ $40 \mathrm{~mm}$ mass was heterogeneous with solid and cystic components (fig. 1) and showed encapsulation. No vascular involvement was observed. MRI showed that the tumor was ovoid and had both solid-to-cystic components; its borders were smooth with some encapsulation. There was no calcification, and the Wirsung duct was not dilated. After injection, the enhancement pattern was heterogeneous. This aspect was considered typical of a SPPT. Endoscopic ultrasound examination showed a similar aspect, and microbiopsies were performed. Collagenic axes with cylindric cells were clearly identified upon pathological examination. Immunohistochemistry showed positivity to vimentin and beta-catenin, and the progesterone receptor was observed. A pancreaticoduodenectomy was then performed. Pathological examination revealed that the aspect was typical of SPPT; there was no sign of malignancy and none of the 18 lymph nodes was involved. Four years later, when she underwent a CT scan because her breast cancer recurred, 4 nodules, ranging from 1 to $4 \mathrm{~cm}$ in diameter, were observed in the right liver lobe, segments VI and VII. All tumors had solidocystic aspects that were very close on CT scan and MRI (fig. 2) to what had been initially observed in the pancreatic mass. Additionally, a liver biopsy confirmed the diagnosis of liver metastases from the pancreatic SPPT and ruled out the possibility of breast cancer extension. After portal vein embolization, she benefited from an extended right hepatectomy. Unfortunately, upon pathological examination, in addition to the known supracentimetric lesions, $17 \mathrm{mi}$ nute metastatic deposits were observed in the removed liver. All tumors corresponded to metastases from the pancreatic SPPT. Four months later, some small deposits were observed in the left liver, and systemic therapy with gemcitabine was initiated.

\section{Discussion}

Frantz's tumors, or SPPT, are uncommon pancreatic tumors. A very large Chinese series reported 553 cases of SPPT [1]. The male:female ratio was 1:8.4, and the mean age was 27 years. The first clinical signs are usually minors despite a tumor size of $8 \mathrm{~cm}$ at diagnosis and a tumor located in the pancreatic head in $40 \%$ of cases. At diagnosis, $<10 \%$ of cases had signs of malignancy with metastases or locoregional (main vessel) invasion. The imaging features were analyzed in a Korean series of 42 histologically proven cases, including 30 cases that were larger than $3 \mathrm{~cm}$ and 12 cases that were smaller [2]. Large SPPTs are usually typical with the following features: ovoid shape, mixed solid and cystic components, smooth borders with a sharp margin and frequent encapsulation. Two-thirds of the cases have calcifications (peripheral rim), and the enhancement patterns during the pancreatic phase are heterogeneous. Additionally, pancreatic duct dilatation is uncommon. In some cases, the aspect is atypical with the following features: purely solid, irregular border, no clear encapsulation, homogeneous enhancement and, sometimes, dilatation of the pancreatic duct. Small SPPTs are very frequently atypical with the following features: round, purely solid, margin frequently indistinct, homogeneous enhancement pattern during the pancreatic phase and dilatation of the Wirsung duct. Such small SPPTs can mimic pancreatic adenocarcinoma. Upon pathological examination, the tumors are usually well encapsulated, containing spongy areas and altering between solid and cystic areas. The solid portion is composed of uniform cells with well-vascularized stroma. Immunohistochemistry showed that all cases are positive for vimentin, and they are frequently positive for alpha 1 antitrypsin, neuron specific enolase, beta catenin and progesterone receptor, while the estrogen receptor is never expressed [3]. Some molecular alterations, such as the expression of CTNNB1 mutations, are frequent, while those that are usually observed in pancreatic adenocarcinoma (KRAS, p53 
Lestelle et al.: Solid Pseudopapillary Tumor of the Pancreas: One Case with a Metastatic Evolution in a Caucasian Woman

and SMAD 4) are not observed [4]. These results suggest that these two entities are distinct. Transcriptional studies indicate that the activation of the Wnt/beta catenin pathway is frequently observed.

After curative resection (305 cases) in the Chinese series, only 11 cases had local recurrence, and 2 cases had hepatic metastases. Some signs are found in malignant SPPTs through imaging, including capsule rupture and intracystic budding. The overall prognosis is excellent, with a 5-year overall survival of $96.9 \%$ in the Chinese series. In case there are liver metastases, surgery is the best option, but many other treatments have been proposed for unresectable metastases, including chemoembolization. Of note, one case of spontaneous regression has been reported. No large series have provided data on the efficacy of systemic treatments.

In summary, these tumors are likely uncommon, particularly among small pancreatic solid tumors, and their histopathological presentation is usually very different from that of pancreatic adenocarcinoma. After fine needle biopsy (during endoscopic ultrasound), the analysis of KRAS mutations can be of interest in order to differentiate between SPPT and pancreatic adenocarcinoma. The overall prognosis is excellent; however, malignancy is observed in some cases with locoregional recurrences or hepatic metastases. The treatment of these cases is not well known.

\section{Statement of Ethics}

The patient gave her informed consent regarding this publication.

\section{Disclosure Statement}

No conflict of interest has to be disclosed about this topic.

\section{References}

1 Yu PF, Hu ZH, Wang XB, Guo JM, Cheng XD, Zhang YL, Xu Q: Solid pseudopapillary tumor of the pancreas: a review of 553 cases in Chinese literature. World J Gastroenterol 2010;14:1209-1214.

-2 Baek JH, Lee JM, Kim SH, Kim SJ, Kim SH, Lee JY, Han JK, Choi BI: Small $(\leq 3 \mathrm{~cm})$ solid pseudopapillary tumors of the pancreas at multiphasic multidetector CT. Radiology 2010;257:97-106.

-3 Uppin SG, Hui M, Thumma V, Challa S, Uppin MS, Bheerappa N, Sastry RA, Paul TR, Prayaga AK: Solidpseudopapillary neoplasm of the pancreas: a clinicopathological and immunohistochemical study of 33 cases from a single institution in Southern India. Indian J Pathol Microbiol 2015;58:163-169.

4 Terris B, Cavard C: Diagnosis and molecular aspects of solid-pseudopapillary neoplasms of the pancreas. Semin Diagn Pathol 2014;31:484-490. 


\section{Case Reports in Oncology}

\begin{tabular}{l|l}
\hline Case Rep Oncol 2015;8:405-408 \\
\hline DOI: 10.1159/000441022 & $\begin{array}{l}\text { (c) 2015 The Author(s). Published by S. Karger AG, Basel } \\
\text { www.karger.com/cro }\end{array}$ \\
\hline
\end{tabular}

Lestelle et al: Solid Pseudopapillary Tumor of the Pancreas: One Case with a Metastatic Evolution in a Caucasian Woman

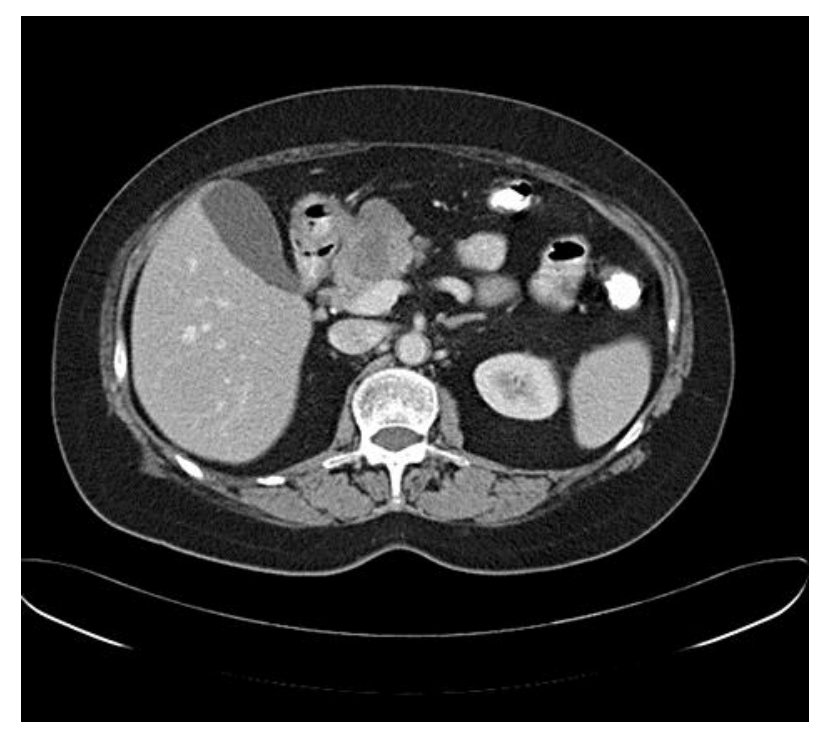

Fig. 1. CT scan aspect of a $60 \times 40 \mathrm{~mm}$ solidocystic tumor of the pancreatic head.

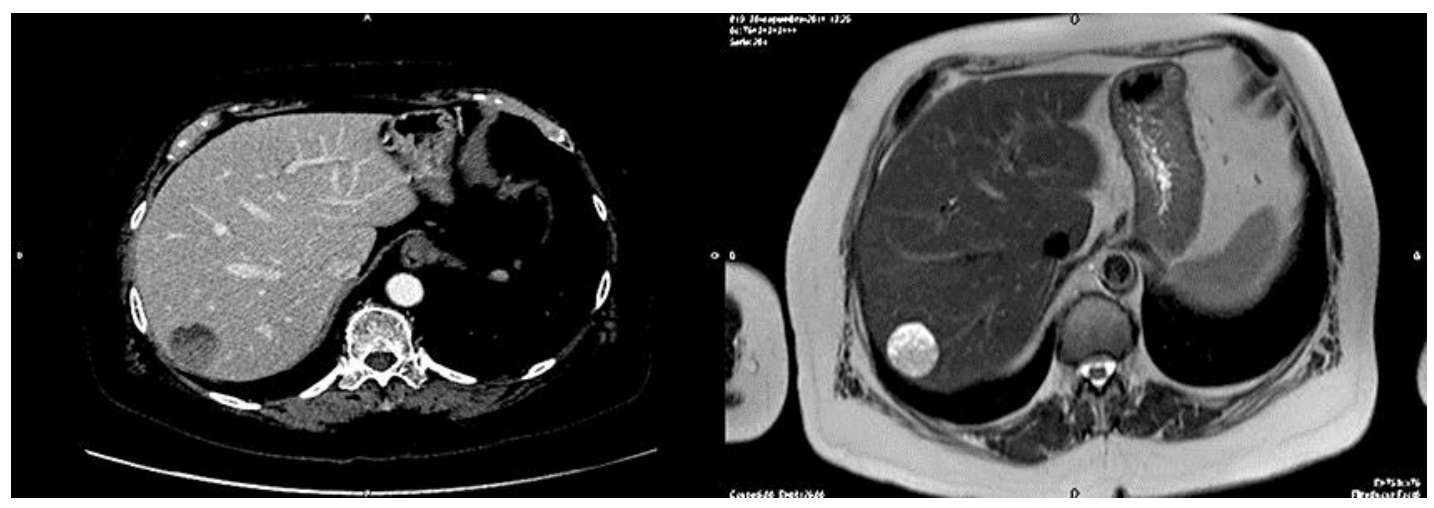

Fig. 2. CT scan and MRI aspect of the main liver metastases showing a similar aspect of solidocystic mass. 